구리, 니켈, 코발트, 철 混合溶液으로부터 구리의 除去

中朴庚鎬* ・南哲祐* ・ 金賢鎬* · S.P. Barik $* * * *$

*韓國地質資源研究院 鑛物資源研究本部

**聯合大學院大學校(UST)， 資源循環工學專攻

\title{
Removal of Copper from the Solution Containing Copper, Nickel, Cobalt and Iron
}

\author{
*Kyung Ho Park*, Chul Woo Nam*, Hyun Ho Kim* and Smruti Prakash Barik**** \\ *Mineral Resource Research Division, Korea Institute of Geoscience \& Mineral Resources (KIGAM) \\ **Resources Recycling, University of Science and technology (UST)
}

\section{요 약}

니켈, 코발트와 철의 혼합용액에 미량 함유되어 있는 구리 (399 ppm 구리, $208 \mathrm{ppm}$ 철, $15.3 \mathrm{~g} / \mathrm{L}$ 니켈, $2.1 \mathrm{~g} / \mathrm{L}$ 코발트)를 분리, 제거를 위한 방법들을 검토하였다. 중화침전법의 경우 용액의 $\mathrm{pH}$ 가 7.0 에서 구리는 철과 함께 전 부 수산화물로 침전, 제거되었으나 니켈과 코발트의 일부도 함께 침전되었다. 황화침전법의 경우 $1.25 \%$ 농도의 $\mathrm{Na}_{2} \mathrm{~S}$ 를 구리의 2 당량비 첨가하고 용액의 $\mathrm{pH}$ 가 1.0 인 경우 구리가 $99.7 \%$ 제거 되었다. TP207 양이온 흡착제를 사용한 이온교환수지법은 평형 $\mathrm{pH} 2.0$ 에서 구리만이 선택적으로 흡착되었으며 탈착용액으로는 $5 \%$ 황산이 적당하였다.

주제어 : 구리제거, 침전, 수산화물, 황화물, 이온교환수지

\begin{abstract}
The methods to separate and remove copper in the mixed solution ((399 ppm Cu, 208 ppm Fe, $15.3 \mathrm{~g} / \mathrm{L} \mathrm{Ni}, 2.1 \mathrm{~g} / \mathrm{L} \mathrm{Co})$ with nickel, cobalt and iron were investigated. With hydroxide precipitation method, copper and iron ions were completely precipitated and removed from the solution at $\mathrm{pH} 7$ while some nickel and cobalt also were precipitated. $99.75 \%$ copper could be precipitated and removed as copper sulfide from the solution with adding $\mathrm{Na}_{2} \mathrm{~S}(1.25 \mathrm{w} / \mathrm{v}$ concentration) of 2 times equivalent of $\mathrm{Cu}$ at $\mathrm{pH}$ 1. Copper was selectively absorbed on TP 207 ion exchange resin at equilibrium pH 2.0 and could be eluted from copper-loaded resin using $5 \% \mathrm{H}_{2} \mathrm{SO}_{4}$.
\end{abstract}

Key words : copper removal, precipitation, hydroxide, sulphide, ion exchange

\footnotetext{
* Received : September 17, $2013 \cdot$ Revised : October 11, 2013 • Accepted : October 23, 2013

†Corresponding Author : Kyung Ho Park (E-mail : khpark@kigam.re.kr)

Mineral Resources Research Division, Korea Institute of Geoscience \& Mineral Resources, 124 Gwahang-no, Yuseong-gu, Daejeon, 305-350 Korea

Tel : +82-42-868-3601/ Fax : +82-42-868-3468

(C) The Korean Institute of Resources Recycling. All rights reserved. This is an open-access article distributed under the terms of the Creative Commons Attribution Non-Commercial License (http://creativecommons.org/licenses/by-nc/3.0/), which permits unrestricted non-commercial use, distribution and reproduction in any medium, provided the original work is properly cited.
} 
1. 서

전해채취법에 의하여 니켈과 코발트를 금속으로 회수 할 경우 이들의 순도는 전해액중에 포함되어 있는 불순 원소에 의하여 크게 영향을 받는다. 용액중에 구리가 포 함되어 있을 경우에는 구리가 니켈이나 코발트 이온보 다 쉽게 금속으로 환원되어 제조되는 니켈이나 코발트 의 순도에 큰 영향을 미친다. 한편 니켈과 코발트를 염, 산화물 또는 분말 형태로 제조할 경우에도 용액중에 불 순물로 함유되는 있는 구리는 최종제품의 순도를 떨어 뜨린다. 따라서 니켈과 코발트의 회수공정을 행하기 전 에 용액으로부터 구리를 반드시 제거하여만 한다.

한국지질자원연구원에서는 건식-습식 혼합법에 의한 망간단괴로부터 구리, 니켈 그리고 코발트를 회수하는 공정을 개발하였다. 건식법에서 망간단괴의 용융환원-황 화법으로 제조된 인조매트상을 고온고압침출조에서 묽 은 황산용액으로 침출하면 $12.1 \mathrm{~g} / \mathrm{L} \mathrm{Cu}, 0.21 \mathrm{~g} / \mathrm{L} \mathrm{Fe}$, $15.2 \mathrm{~g} / \mathrm{L} \mathrm{Ni}, 2.0 \mathrm{~g} / \mathrm{L} \mathrm{Co}$ 의 조성을 가지는 침출용액을 얻게 된다. 이 용액은 LIX84-I를 사용하여 구리의 용매 추출을 행하며 탈거액을 전해폐액으로 사용하는 용매추 출-전해 일관공정을 행하는데 이 경우 raffinate에는 일 정량의 구리가 잔존하게 된다 ${ }^{5-6)}$. 본 공정에서는 약 $0.5 \mathrm{~g} / \mathrm{L}$ 의 구리는 추출되지 않고 니켈, 코발트와 더불어 raffinate중에 잔존하며 고순도의 니켈과 코발트의 회수 를 위하여는 구리를 제거하여야 한다.

이를 위하여 일반적으로 알려져 있는 방법으로는 1 . 용액의 $\mathrm{pH}$ 조절에 의한 수산화구리로 침전 제거 ${ }^{7-8)}, 2$. 철이나 아연을 첨가하여 금속치환법(cementation)으로 구리를 침전 ${ }^{9-10)}$ 3. 황화구리로 침전, 제거 ${ }^{11-14)}$ 4. 이온 교환수지법에 의한 구리의 선택적 흡착, 제거 ${ }^{15-17)}$ 등이 있다. 본 고에서는 니켈, 코발트 그리고 철을 함유한 용 액으로부터 구리를 효과적으로 분리하는 방법에 대하여 수산화구리 침전법, 황화구리 침전법 그리고 이온교환 수지법에 대하여 검토하였다. Cementation법은 환원제 로 첨가한 철 또는 아연이 용액중에 이온상태로 용해되 어 니켈과 코발트를 회수하는 후처리공정에서 불순원소 로 작용하기 때문에 본 검토 대상에서 제외하였다.

\section{2. 실험방법}

\section{1. 시료}

본 연구에서 사용한 용액은 망간단괴 중간생성물인 합성매트상의 침출용액을 LIX 84-I를 사용하여 용매추
Table 1. Chemical composition and $\mathrm{pH}$ of solution tested

\begin{tabular}{|c|c|c|c|c|}
\hline $\mathrm{Cu}$ & $\mathrm{Fe}$ & $\mathrm{Ni}$ & $\mathrm{Co}$ & $\mathrm{pH}$ of solution \\
\hline $399 \mathrm{ppm}$ & $208 \mathrm{ppm}$ & $15.3 \mathrm{~g} / \mathrm{L}$ & $2.1 \mathrm{~g} / \mathrm{L}$ & 0.89 \\
\hline
\end{tabular}

출하여 구리를 분리한 raffinate와 조성과 $\mathrm{pH}$ 가 같은 합성용액 (Table 1)을 제조하여 사용하였다. 한편 본 실 험에 사용한 시약은 모두 특급이었다.

\section{2. 실험방법}

2.2.1. 수산화구리 침전

시료 용액 $500 \mathrm{ml}$ 를 $1 \mathrm{~L}$ 용량의 4개의 baffle이 있 는 pyrex 재질의 반응조에 넣은 후 $10 \mathrm{M} \mathrm{NaOH}$ 용액 을 서서히 투입하면서 용액의 $\mathrm{pH}$ 를 변화시켰다. 이 때 용액은 테프론 재질의 교반봉을 사용하여 충분히 교반 (300 rpm) 하면서 수산화구리의 침전 반응을 수행하였 으며 용액의 온도는 상온 $\left(\sim 25^{\circ} \mathrm{C}\right)$ 이었다. 용액의 $\mathrm{pH}$ 가 일정하게 유지되면 10 분 후 $10 \mathrm{ml}$ 를 채취 하여 고 액분리 후 용액의 금속농도를 측정하여 금속들의 침전 율을 계산하였다. 본 실험의 모든 금속농도 분석은 원 자흡광분광분석기 (모델명: Varian SpectrAA-400)를 사 용하였으며 용액의 $\mathrm{pH}$ 측정에는 digital $\mathrm{pH}$ meter (모 델명; Orion 3 star, Thermo Scientific)를 사용하였다.

\subsection{2. 황화구리 침전}

황화구리 생성 침전제로는 $\mathrm{Na}_{2} \mathrm{~S}$ 로서 $\mathrm{Na}_{2} \mathrm{~S}$ 농도 변 화실험의 경우를 제외하고는 $20 \%$ (w/v) 용액 (1.67 mole) 을 사용하였다. 실험방법은 $500 \mathrm{ml}$ 용액에 $200 \mathrm{ml}$ 합성 용액과 일정량의 $\mathrm{Na}_{2} \mathrm{~S}$ 용액을 첨가하여 일정시간 동안 magnetic stirrer를 사용하여 $300 \mathrm{rpm}$ 으로 교반하여 황 화구리의 침전반응을 수행하였으며 이 때의 온도는 상 온이었다. 한편 용액의 $\mathrm{pH}$ 조절에는 $10 \% \mathrm{NaOH}$ 또는 $48 \% \mathrm{H}_{2} \mathrm{SO}_{4}$ 를 사용하였다. 반응 완료 후 용액의 $\mathrm{pH}$ 를 측정하고 여과를 행한 후 용액중의 금속농도를 측정하 여 이들의 침전율을 구하였다.

\subsection{3. 이온교환수지법}

본 실험에 사용한 수지인 chelating ion exchange resin은 TP 207로서 Lanxess, Korea Ltd에서 제공받았 으며 일반적 성질은 Table 2와 같다. 용액중의 구리의 흡착 및 탈착은 batch과 column 두 종류의 실험을 수 행하였으며 실험온도는 상온 $\left(\sim 25^{\circ} \mathrm{C}\right)$ 이었다. Batch 실 험은 수평형 thermostat shaker (모델: BS 21, Jeio Tech, Korea)를 사용하였으며 $250 \mathrm{ml}$ 용량의 삼각슬라 
Table 2. General physical properties of Lewatit TP 207

\begin{tabular}{|l|l|}
\hline Functional group & Iminodiactic acid \\
\hline Matrix & Cross linked polystyrene \\
\hline Structure & Macro porous \\
\hline $\mathrm{pH}$ range & $0-14$ \\
\hline Bead size & $0.4-1.25 \mathrm{~mm}$ \\
\hline Capacity & $2.4 \mathrm{mmol} /(\mathrm{g}$ of resin) \\
\hline
\end{tabular}

스크에 용액 $100 \mathrm{ml}$ 와 일정량의 흡착제를 첨가하여 흡 착 및 탈착실험을 행하였다. 한편 column 실험은 glass column (높이 $30 \mathrm{~cm}$, 반경 $2 \mathrm{~cm}$ )를 사용하였으며 정량 펌프를 사용하여 일정량의 유속의 용액을 주입하고 배 출되는 용액의 금속성분을 분석하여 흡착율과 탈착율을 구하였다.

\section{3. 실험결과 및 고찰}

\section{1 수산화구리 침전}

Fig. 1은 용액의 $\mathrm{pH}$ 를 5.49 에서 7.43 까지 변화시켰을 경우 금속이온이 수산화물로의 침전율을 나타낸 것이다. 그림에서 보는 바와 같이 철은 $\mathrm{pH} 5.49$ 에서는 $97.3 \%$ 가 $\mathrm{Fe}(\mathrm{OH})_{3}$ 로 침전되었으며 $\mathrm{pH} 5.76$ 이상에서 전부 침 전됨을 알 수 있다. 한편 구리의 경우는 용액의 $\mathrm{pH}$ 가 증가함에 따라 $\mathrm{Cu}(\mathrm{OH})_{2}$ 로의 침전율도 증가하여 $\mathrm{pH}$ $5.76,6.19$ 그리고 6.75 에서 각각 $58.4 \%, 87.5 \%$ 그리 고 $98.8 \%$ 으로 침전율을 보이고 $\mathrm{pH}$ 7.0에서는 모든 구 리가 침전되었다. 한편 니켈과 코발트는 $\mathrm{pH}$ 가 6.10 이 하에서는 전혀 침전되지 않으며 $\mathrm{pH} 7.0$ 에서는 각각 $1.5 \%$ 와 $2.3 \%$ 의 침전율을 보이고 있다. 한편 $\mathrm{pH}$ 가 7 이상에서는 니켈과 코발트의 침전율이 급격히 증가하여 $\mathrm{pH} 7.4$ 에서의 니켈과 코발트의 침전율은 각각 $19 \%$ 와 $15 \%$ 까지 증가한다. 본 실험결과로부터 침출용액으로부 터 구리와 철의 효과적인 수산화물로의 침전, 분리를 위한 적합한 $\mathrm{pH}$ 는 7 부근 임을 알 수 있다. 그러나 앞에서 설명한 바 같이 이 경우 약간의 니켈과 코발트 도 구리와 함께 침전되는데 이 침전물들은 침출조로 보 내어 재사용할 수 있다. 이 방법의 이점 중의 하나는 철도 동시에 같이 침전시킬 수 있으며 최종 용액의 $\mathrm{pH}$ 가 7 정도이여서 후공정인 코발트와 니켈의 분리, 회수인 용매추출를 위하여 $\mathrm{pH}$ 를 용액의 $\mathrm{pH}$ 가 5.5이상 이 요구되는데 이를 위한 별도의 $\mathrm{pH}$ 조절이 요구되지 않는다.

J. of Korean Inst. Resources Recycling Vol. 22, No. 6, 2013

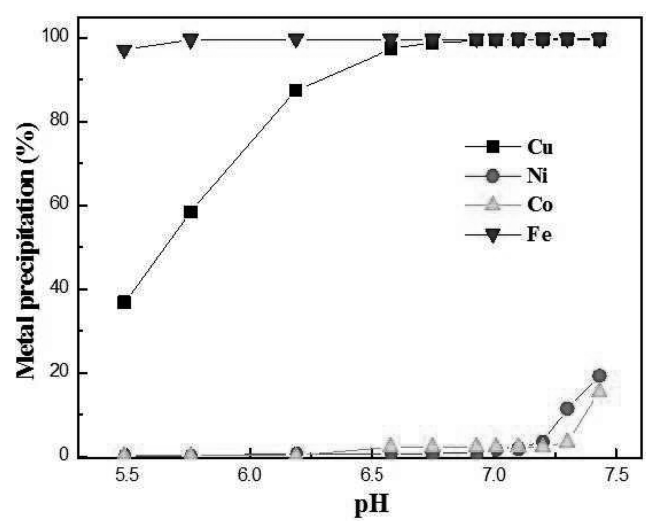

Fig. 1. Effect of solution $\mathrm{pH}$ on metal hydroxide precipitation.

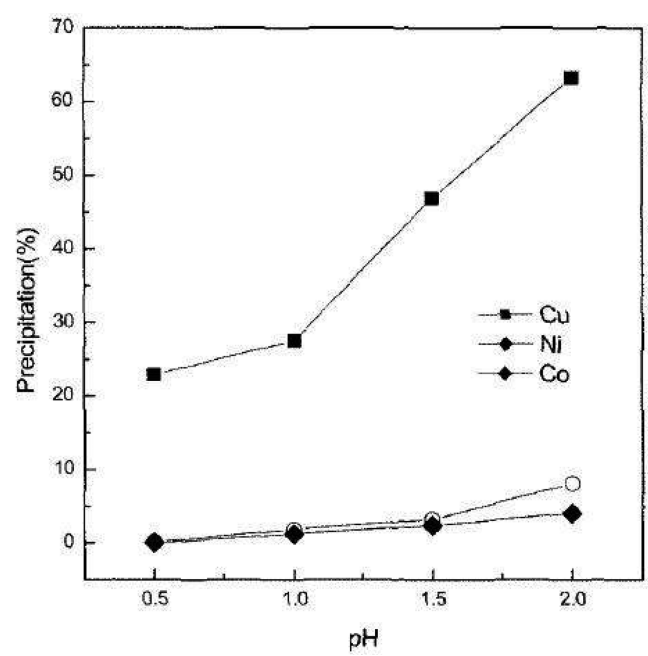

Fig. 2. Effect of solution $\mathrm{pH}$ on metal sulfide precipitation.

\section{2. 황화구리 침전 ${ }^{18)}$}

Fig. 2는 $\mathrm{Na}_{2} \mathrm{~S}$ 용액을 구리양의 1 당량비로 첨가하 였을 때 반응 후 용액의 $\mathrm{pH}$ 변화에 따른 구리의 침전 율을 나타낸 것이다. 이 때의 실험조건은 온도 $25^{\circ} \mathrm{C}$, 교반시간 30 분 이었다. 그림에서 알 수 있는 바와 같이 용액의 $\mathrm{pH}$ 가 높을수록 구리의 침전율도 증가하였다. 즉 용액의 $\mathrm{pH}$ 가 0.5 에서는 구리의 침전율은 $22.9 \%$ 이였으 나 $\mathrm{pH}$ 가 $1.0,1.5$ 그리고 2.0 으로 증가함에 따라 구리 의 침전율도 $27.5 \%, 46.9 \%$ 그리고 $63.2 \%$ 로 증가하였 다. 한편 니켈과 코발트는 용액의 $\mathrm{pH}$ 가 0.5 에서는 거의 침전되지 않았으나 $\mathrm{pH}$ 가 $1.0,1,5$ 그리고 2.0 으로 증가 함에 따라 침전율이 각각 $1.8 \%, 3.2 \%, 8.1 \%$ 와 $1.2 \%$, $2.4 \%, 4.0 \%$ 로 증가하였다. 이 경우 철은 $\mathrm{pH} 2.0$ 에서 도 전혀 침전되지 않았다. 


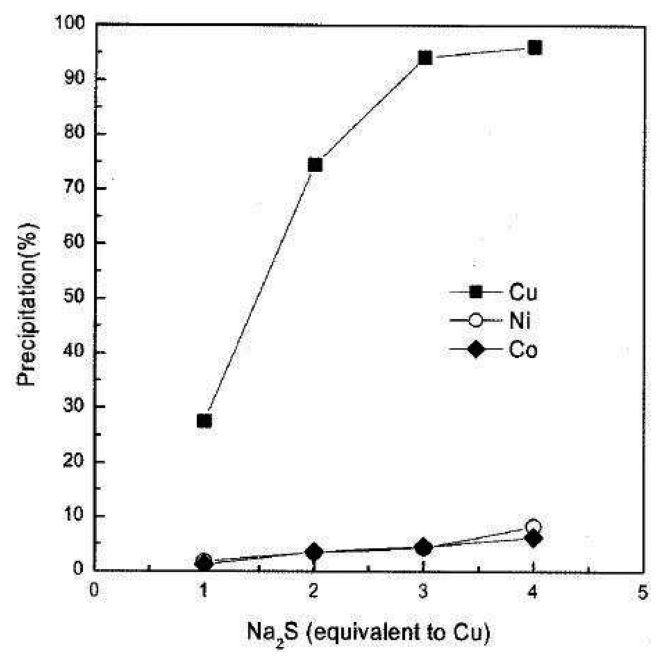

Fig. 3. Effect of amount of $\mathrm{Na}_{2} \mathrm{~S}$ added on metal sulfide precipitation.

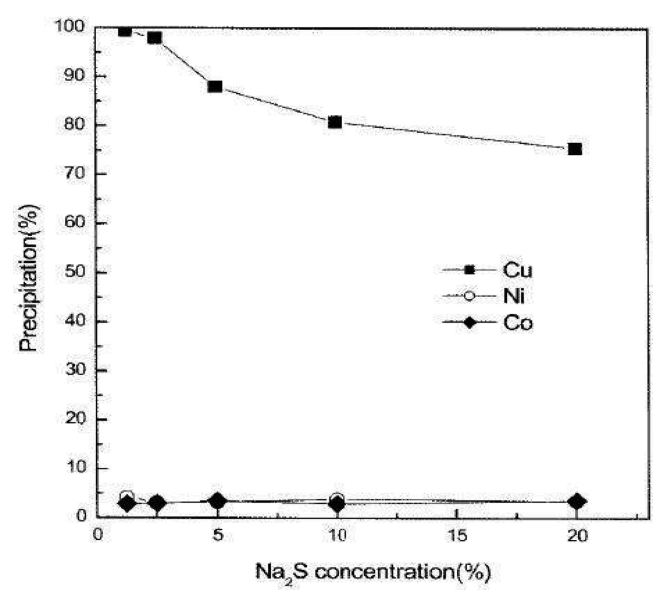

Fig. 4. Effect of $\mathrm{Na}_{2} \mathrm{~S}$ concentration on metal sulfide precipitation.

Fig. 3은 용액의 $\mathrm{pH} 1.0$, 교반시간 30 분, 온도 $25^{\circ} \mathrm{C}$ 에서 $\mathrm{Na}_{2} \mathrm{~S}$ 첨가량에 따른 각 금속성분의 침전율을 나 타낸 것이다. 그림에서 보는 바와 같이 $\mathrm{Na}_{2} \mathrm{~S}$ 첨가량이 증가함에 따라 구리의 침전율이 급격히 증가하였고 니 켈과 코발트 침전율 역시 증가하였다. 즉 $\mathrm{Na}_{2} \mathrm{~S}$ 의 첨가 량이 구리 당량비은 $1,2,3$ 그리고 4 배 첨가한 경우 구리, 니켈 그리고 코발트의 침전율은 각각 $27.7 \%$, $74.5 \%, 94.1 \%, 96.1 \%$ 와 $1.8 \%, 3.5 \%, 4.3 \%, 8.3 \%$ 그 리고 $1.2 \%, 3.5 \%, 4,5 \%$ 그리고 $6.3 \%$ 이었다.

Fig. 4는 첨가하는 $\mathrm{Na}_{2} \mathrm{~S}$ 의 농도가 구리의 침전율에

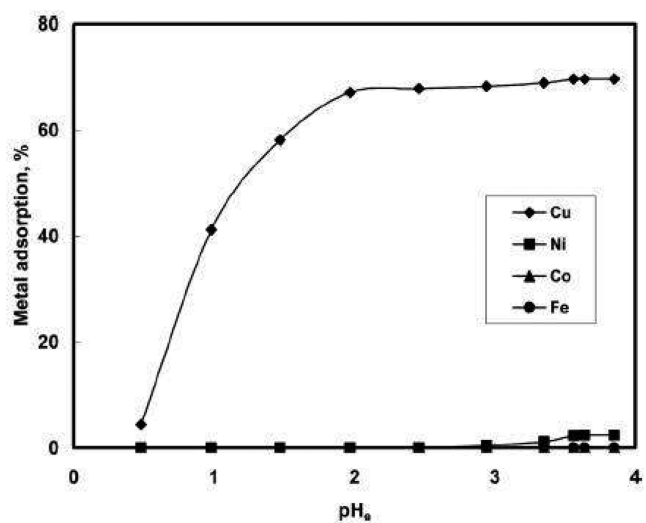

Fig. 5. Effect of equilibrium $\mathrm{pH}$ on adsorption of metal by TP 207.

미치는 영향에 대하여 조사한 것으로 실험조건은 용액 의 $\mathrm{pH} 1.0$, 온도 $25^{\circ} \mathrm{C}$, 교반시간 30 분, $\mathrm{Na}_{2} \mathrm{~S}$ 는 구리 의 2 당량비를 첨가하였다. $\mathrm{Na}_{2} \mathrm{~S}$ 농도가 $1.25 \%$, $2.5 \%, 5 \%, 10 \%$ 그리고 $20 \%$ 인 경우 구리의 침전율 은 각각 $99.7 \%, 97.9 \%, 88.0 \%, 80.9 \%, 75.5 \%$ 로 $\mathrm{Na}_{2} \mathrm{~S}$ 농도가 낮을수록 구리의 침출율이 증가하였다. 한 편 니켈과 코발트의 침전율은 $\mathrm{Na}_{2} \mathrm{~S}$ 농도에 별 영향을 받지 않았다. 실제 조업에 있어서는 농도가 낮은 $\mathrm{Na}_{2} \mathrm{~S}$ 를 사용하는 것은 용액을 희석시키는 결과를 초래한다. 한편 이 방법은 침전 분리된 황화구리의 회수를 위한 재용해가 쉽지 않다는 점과 철은 침전, 제거되는 않는 문제점이 있다.

\section{3. 이온교환수지법 ${ }^{19)}$}

Fig. 5는 용액의 평형 $\mathrm{pH}$ 변화 (0.48-3.85)에 따른 $\mathrm{TP} 207$ 의 구리흡착율을 나타낸 것이다. 실험은 용액 $100 \mathrm{ml}$ 에 흡착제 $0.5 \mathrm{~g}$ 을 첨가하여 상온 $\left(25^{\circ} \mathrm{C}\right)$ 에서 10 시간동안 흡착실험을 행하였다. 그림에서 보는 바와 같 이 평형 $\mathrm{pH}$ 가 0.48 에서 1.97 로 증가함에 따라 구리의 흡착율도 $4.4 \%$ 에서 $67.1 \%$ 로 증가하였으며 $\mathrm{pH} 1.97$ 이상에서는 구리의 흡착율이 더 이상 증가하지 않았다. 한편 니켈의 경우는 평형 $\mathrm{pH} 3$ 이상에서 흡착이 시작 되었으며 코발트와 철(III)은 평형 $\mathrm{pH} 3.85$ 까지 전혀 흡착이 일어나지 않았다. 또한 이 그림으로부터 평형 $\mathrm{pH}$ 1.97에서 TP 207의 최대 구리흡착량은 $68.7 \mathrm{mg} / \mathrm{g}$ 임을 알 수 있다. Fig. 6은 TP 207에 의한 구리의 흡 착에 대한 column 실험결과를 보여주고 있다. 실험조건 은 용액의 초기구리농도 $0.51 \mathrm{~g} / \mathrm{L}, \mathrm{pH} 2.0$, 상온 


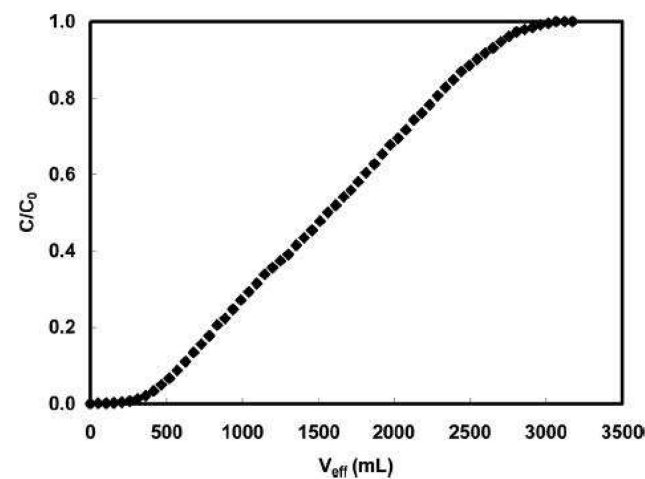

Fig. 6. Break through curve for adsorption of copper on TP 207.

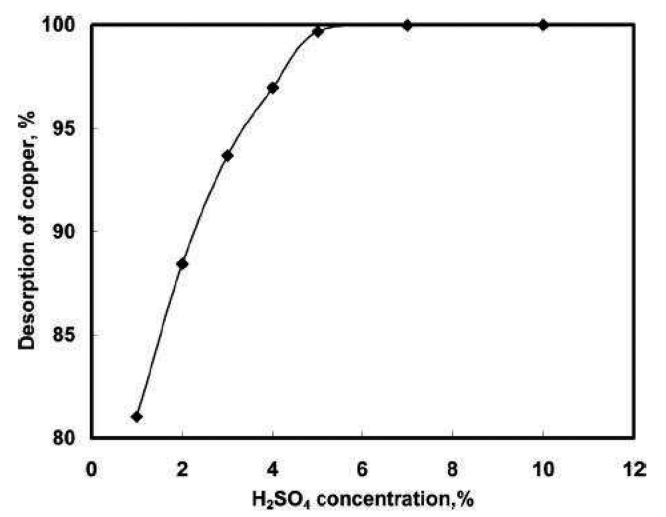

Fig. 7. Effect of $\mathrm{H}_{2} \mathrm{SO}_{4}$ concentration on desorption of copper from TP207.

$\left(25^{\circ} \mathrm{C}\right)$, 사용한 흡착제의 양 $10 \mathrm{~g}$, bed 부피 $26.0 \mathrm{~cm}^{3}$ 그리고 유속은 $5.0 \mathrm{~mL} / \mathrm{min}$ 이었다. 그림에서 보는 바와 같이 breakthrough point는 약 $250 \mathrm{~mL}$ volume에서 얻 어졌으며 약 $2.96 \mathrm{~L}$ 까지는 구리가 흡착되는 현상을 보 였다. 한편 본 실험조건 하에서는 철, 니켈 그리고 코발 트는 전혀 흡착되지 않았다.

Fig. 7은 TP 207에 흡착된 구리의 탈거에 탈거액 (황 산)의 농도의 영향을 나타낸 것이다. 실험조건은 $68.7 \mathrm{mg} / \mathrm{g}$ 의 구리가 흡착된 TP207을 $0.5 \mathrm{~g}$ 을 일정농 도의 황산 $100 \mathrm{~mL}$, 상온에서 10 시간 탈착하였다. 그림 에서 보는 바와 같이 $5 \% \mathrm{H}_{2} \mathrm{SO}_{4}$ 이상에서는 모든 구 리가 탈착되었다. Fig. 8은 5\% 황산을 이용한 column 에 의한 탈착실험 결과이다. 실험조건은 흡착제 $10 \mathrm{~g}$, bed volume $26.0 \mathrm{~cm}^{3}$, 유속 $5.0 \mathrm{~mL} / \mathrm{min}$ 이었다. 그림 에서 보는 바와 같이 약 8 분 후 탈착액중의 구리농도는

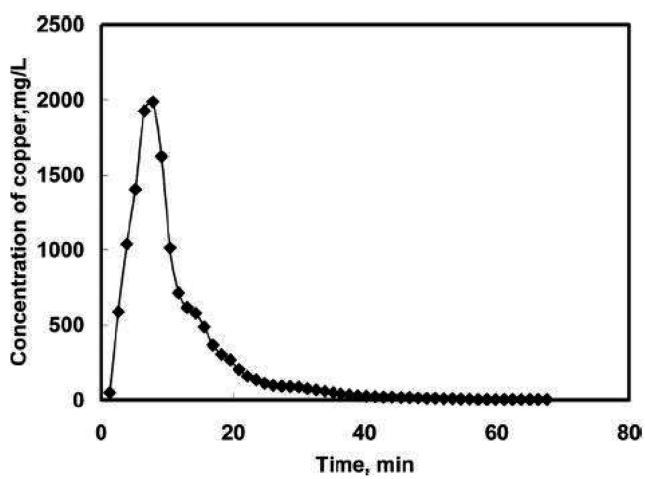

Fig. 8. Elution profile of copper from TP 207.

약 $1.98 \mathrm{~g} / \mathrm{L}$ 의 최대치에 도달하며 구리의 완전한 탈거 를 위하여는 약 60 분 정도가 소요됨을 알 수 있다.

위의 실험결과로부터 알 수 있는 바와 같이 TP 207 수지를 사용하면 철, 니켈 그리고 코발트 혼합용액으로 구리만을 선택적으로 흡착, 분리할 수 있었다. 그러나 이온교환수지방법을 사용하는 것은 앞의 침전법에 비하 여 설비비와 수지의 비용 등 운영비가 많이 들고 철 이온은 제거되지 않는다는 단점이 있다.

\section{4. 결 론}

니켈, 코발트, 철 그리고 구리 혼합용액으로부터 용매 추출-전해공정에 의하여 구리를 분리, 회수하고 남은 여 액 (208 ppm 철, $15.3 \mathrm{~g} / \mathrm{L}$ 니켈, $2.1 \mathrm{~g} / \mathrm{L}$ 코발트)에 미 량 함유되어 있는 구리 $(399 \mathrm{ppm})$ 를 제거를 위한 방법 들을 검토하였다. 중화침전법의 경우 용액의 $\mathrm{pH}$ 가 7.0 에서 구리는 철과 함께 모두 수산화물로 침전, 제거되 었으나 $1.5 \%$ 니켈과 $2.3 \%$ 코발트도 함께 침전되었다. 황화침전법의 경우 $1.25 \%$ 농도의 $\mathrm{Na}_{2} \mathrm{~S}$ 를 구리의 2 당 량비 첨가하고 용액의 $\mathrm{pH}$ 가 1.0 인 경우 구리가 $99.7 \%$ 제거되었으며 일부 니켈과 코발트도 함께 침전되나 철 은 침전되지 않았다. TP207 양이온 흡착제를 사용한 이온교환수지법은 평형 $\mathrm{pH} 2.0$ 에서 구리만이 선택적으 로 흡착되었으며 탈착용액으로는 $5 \%$ 황산이 적당하였 다. 니켈, 코발트 그리고 철 혼합용액 중에 함유되어 있 는 미량의 구리를 제거하는 방법들은 나름대로의 장단 점을 가지고 있으며 설비의 투자비, 운영비 그리고 후 처리공정 등을 고려하여 최상의 방법을 선정하는 것이 필요하다. 


\section{감사의 글}

본 연구는 해양수산부의 연구비 지원으로 수행되었으 며 이에 감사드립니다.

\section{참고문헌}

1. W.J. Jee, et.al., 2010: Removal of copper from coblat sulfate electrolyte by ion-exchange, T. Nonferr. Metal Soc., 20, pp. 1534-1540.

2. E. Kuzeci, and R. Kammel, 1994: Effect of metallic and D2EHPA impurities on nickel electrowinning from aqueous sulphate baths, J. of Applied Electrochemistry, 24, pp730-736.

3. K.H. Park and C.W. Nam, 2002: A study on the recovery of valuable metals from manganese nodules by reductionsmelting and leaching rrocess", J. of Korean Materials, 15(8), pp. 15-23.

4. K.H. Park, C.W.Nam and H.I.Kim, 2004: High temperature and high pressure sulfuric acid leaching of $(\mathrm{Cu}-\mathrm{Ni}-\mathrm{Co}-\mathrm{Fe})$ matte, J. of the Korean Society of Geosystem Engineering, 41(5), pp. 1-5.

5. G.M. Ritcey and A.W. Ashbrook, 1979: Solvent extraction, Part II, Elsevier, Amsterdam.

6. B. R. Reddy, Kyung Ho Park and D. Mohapatra, 2007: Process development for the separation and recovery of copper from sulphate leach liquors of manganese nodules matte using LIX 84 and LIX 973N, Hydrometallurgy, 87, pp. 51-57.

7. E. Jackson, 1986: Hydrometallurgical extraction and reclamation, pp158, John Wiley \& Sons, New York, pp. 158.

8. B.R. Reddy and K.H.Park, 2007: Process for the recovery of cobalt and nickel from sulphate leach liquors with saponified Cyanex 272 and D2EHPA, Separation Science and Technology, 42, pp. 2067-2080.

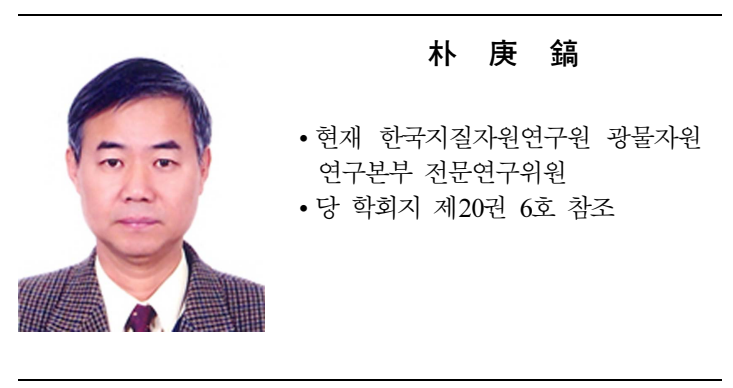

9. I.M. Ahmed, Y.A. El-Nadi and J.A. Daoud, 2011: Cementation of copper from spent copper-pickle sulfate solution by zinc ash, Hydrometallurgy, 110, pp. 62-66.

10. T. Stefanowicz, M Osinska and S. Napieralsa-Zagozda, 1997: Copper recovery by the cementation method" , Hydrometallurgy, 47, pp. 69-90.

11. A.E. Lewis, 2010: Review of metal sulphide precipitation" , Hydrometallurgy, 104, pp. 222-234.

12. R.M.M. Sampaio, et.al, 2009: Selective precipitation of $\mathrm{Cu}$ from $\mathrm{Zn}$ in a $\mathrm{pS}$ controlled continuously stirred tank reactor, J. of Hazardous Materials, 165, pp 256-265.

13. J. Jandova, et.al., 2005: Separation of copper and cobaltnickel sulphide concentrates during processing of manganese deep ocean nodules, Hydrometallurgy, 77, pp. 75-79.

14. Y Liu and M.S. Lee, 2013: Separation of cobalt and nickel from aqueous solution", J. of Korean Inst. of Resources Recycling, 22(1), pp. 11-19.

15. A.A. Atia, A.M. Donia and A.M. Yousif, 2008:, Removal of some hazardous heavy metals from aqueous solution using magnetic chelating resin with iminodiacetate functionality, Sep. Purf. Technol. 61, pp. 348-357.

16. N.V. Ngugen, et.al., 2009: Copper recovery from low concentration waste solution using Dowex G-26 resin, Hydrometallurgy, 97, pp. 237-242.

17. R. Raghavan and C.V. Bhatt, 1998: Comparative study of certain ino-exchange resins for application in copperbearing process solutuions, Hydrometallurgy, 50, pp. 169183.

18. K.H. Park, et.al., 2005: Precipitation of $\mathrm{Cu}$ as the sulphide from sulphate solution containing $\mathrm{Cu}, \mathrm{Ni}$ and $\mathrm{Co}$, J. of Korean Inst. of Resources Recycling, 14(8), pp. 16-20.

19. K.H. Park, P.K. Parhi and N.H. Kang, 2012: Studies on removal of low content copper from the sea nodule auqeous solution using the cationic resin TP207, Separation Science and Technology, 47, pp. 1-11.

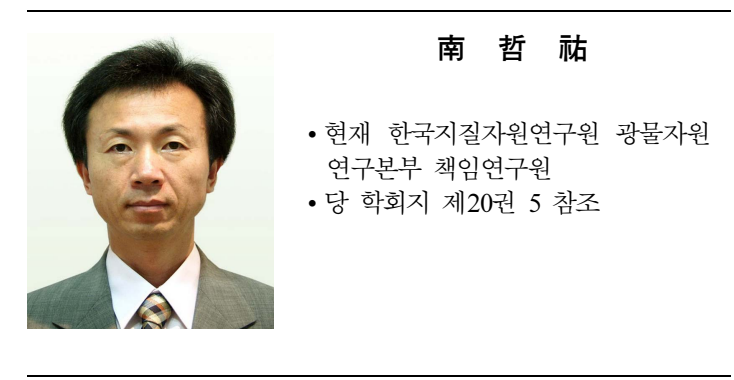



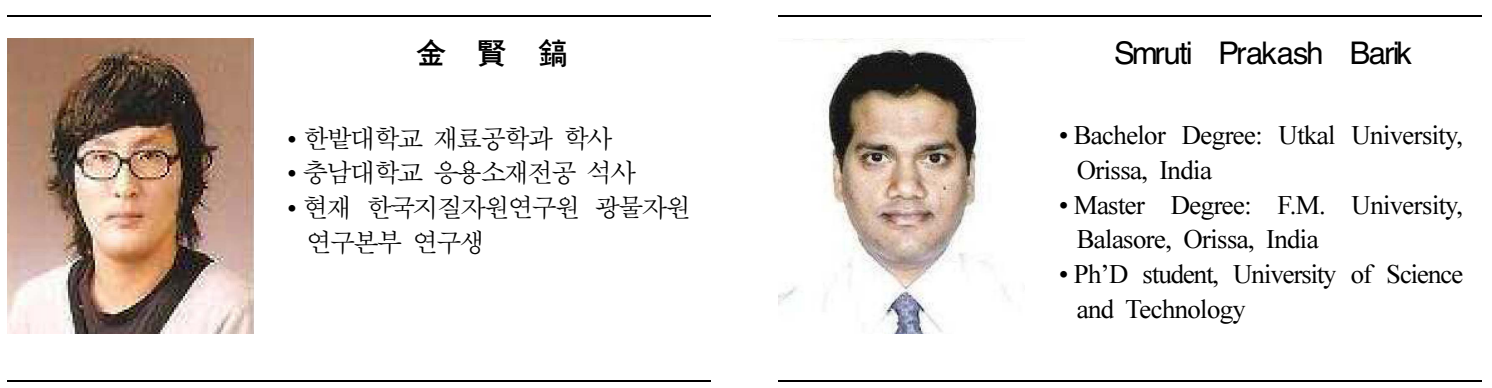

\section{공 지 사 항}

국문학회지 “資源리싸이클링” 한글만 사용

그간 학회지에 게재되는 모든 원고의 국문제목과 저자명, 소속 등에 한자를 혼용하도록 권장하였습니다.

그러나 한자로 작성하는데 적잖은 번거로움이 있다는 회원분들의 의견과 뜻을 오기하여 작성하는 경우가 간혹 발생하여 2014년부터 발간되는 학회지(23권 1호부터)는 한글로 작성하도록 원칙을 수정하였습니다.

이점 참고하셔서 작성하여 주시고, 훌륭한 원고 많이 투고하여 주시기 바랍니다. 